\title{
O mito da homogeneidade biológica na população paleoíndia de Lagoa Santa: implicações antropológicas ${ }^{1}$
}

\author{
Walter A. Neves ${ }^{2}$ \& João Paulo V. Atui ${ }^{3}$ \\ Laboratório de Estudos Evolutivos Humanos \\ do Departamento de Biologia - IB/USP
}

\begin{abstract}
RESUMO: Desde sua primeira descoberta entre 1842 e 1843, pelo naturalista dinamarquês Peter W. Lund, os remanescentes ósseos humanos de Lagoa Santa, Brasil Central, estavam destinados a impactar de forma indelével os estudos sobre as origens dos primeiros americanos. Entre sua primeira descoberta e a década de 1970, a palavra homogeneidade biológica foi sempre aplicada a esses remanescentes como sinônimo de identidade biológica populacional. Mello e Alvim (1977; ver também Mello e Alvim et al., 19831984) associou a esse termo um novo significado: o de que tal população apresentava uma diversidade biológica extremamente reduzida, quando comparada a outras populaçôes humanas, tendo sugerido, a partir daí, que a população antiga de Lagoa Santa teria sido formada originalmente por poucos indivíduos e vivido de forma isolada de outras populaçôes contemporâneas. Essa sugestão teve grande impacto na comunidade arqueológica brasileira, levando alguns arqueólogos a tentar compreender certos aspectos da cultura material e da organização social desses primeiros americanos da perspectiva do isolamento. Neste trabalho demonstramos, com a ajuda de cálculos simples sobre quantificação em antropologia, disponíveis na literatura há pelo menos um século, que a proposta de Mello e Alvim (1977) não resiste nem mesmo a uma análise superficial dos dados disponíveis sobre a variabilidade craniométrica desses primeiros americanos. Contrariamente à proposta daquela autora, a população paleoíndia tardia de Lagoa Santa está entre as populaçôes humanas mundiais mais diversas biologicamente.
\end{abstract}


W. A. Neves \& J. P. V. Atui. O mito da homogeneidade biológica...

PALAVRAS-CHAVE: variabilidade intrapopulacional, paleoíndios, coeficiente de variação, isolamento genético.

\section{Introdução}

Desde sua descoberta inicial por Peter W. Lund em 1842-1843 (Lund, 1844), os remanescentes ósseos humanos exumados dos abrigos e das grutas da região do carste de Lagoa Santa vêm exercendo grande fascínio entre a comunidade bioantropológica e arqueológica nacional e estrangeira (para uma revisão sobre esse interesse até o final da década de 1970, ver Mello e Alvim, 1977; Soto-Hein, 1994).

Pode-se dizer que, desde o achado dos cerca de 30 esqueletos humanos na gruta do Sumidouro, os remanescentes ósseos humanos de Lagoa Santa estavam destinados a impactar de forma indelével o estudo da presença dos humanos no continente americano e a própria história dos estudos evolutivos humanos. Para legitimar essa afirmação, basta relembrar aqui apenas dois eventos, cronologicamente extremos, a eles ligados: a proposição de Lund (1844) de que esses esqueletos, por estarem associados à megafauna extinta, eram de grande antiguidade, sugerindo a presença do homem no Novo Mundo pelo menos a partir do final do Pleistoceno - coisa impensável à sua época -, e a recente demonstração de que o esqueleto humano mais antigo até o momento conhecido na América, popularizado por um de nós (WAN) como "Luzia”, exumado nos anos 1974-1975 da Lapa Vermelha IV, como de resto toda a população paleoíndia de Lagoa Santa, mostra grande afinidade morfológica com os atuais africanos e australianos, sem prejuízo a uma origem asiática (Neves et al., 1998; 1999a; 1999b; 2003; Powell \& Neves, 1999). 
Revista de Antropologia, São Paulo, USP, 2004, v. 47 № 1.

Diferentemente desses estudos de impacto internacional, que ocuparam os extremos cronológicos do final do século XIX/início do século XX e final do século XX/início do século XXI, os estudos relativos a esses importantes remanescentes ósseos humanos, desenvolvidos neste intervalo por bioantropólogos brasileiros, não lograram ultrapassar os limites do consumo doméstico. Esse fenômeno só pode ser compreendido por meio de uma análise crítica da bioantropologia elaborada no Brasil durante as décadas de 1960, 1970 e parte da de 1980, tarefa esta que ultrapassa o escopo do presente trabalho (para uma revisão sobre o tema ver Neves, 1988).

Eminentemente descritivos e tipológicos, destituídos de qualquer base teórica aceitável mesmo para a época em que foram gerados, esses estudos não só promoveram um afastamento quase irreconciliável entre a antropologia biológica e a antropologia sociocultural no país, afastamento este profeticamente previsto por Luis de Castro Faria, pelo menos uma década antes (Faria, 1952), como também cristalizaram mitos injustificáveis entre a comunidade arqueológica nacional, mitos estes que tiveram grande propriedade anti-heurística no que tange ao avanço da compreensão da biologia das populações pré-históricas que ocuparam o território brasileiro.

O objetivo deste trabalho é apresentar, de forma sucinta, a construção de um desses mitos, o da homogeneidade biológica da população paleoíndia de Lagoa Santa, bem como desconstruí-lo, por meio de ferramentas quantitativas há muito disponíveis na literatura. Essa desconstrução visa ao estabelecimento de parâmetros quantitativos que possam embasar interpretações verossímeis sobre a organização social e o comportamento das populações pré-históricas brasileiras por parte da comunidade arqueológica, esta também, na maioria das vezes, desinformada e acrítica sobre o potencial informativo dos remanescentes ósseos humanos que exumam. 
W. A. Neves \& J. P. V. Atui. O mito da homogeneidade biológica...

\section{A construção do mito}

O conceito de homogeneidade biológica aplicado à população esqueletal de Lagoa Santa transformou-se ao longo do tempo. Inicialmente a palavra homogeneidade foi utilizada no sentido de identidade biológica. Assim aplicada, a palavra homogeneidade levou à aceitação de que os cerca de 30 esqueletos exumados por Lund no Sumidouro representavam apenas uma "raça" humana, diga-se de passagem, uma "raça pura". Num segundo momento, mais claramente a partir dos anos 1970, foi atribuído ao termo "homogeneidade biológica" um segundo significado, sem prejuízo ao primeiro: a idéia de que, além de representar uma única população biológica, a variabilidade intrapopulacional dos paleoíndios de Lagoa Santa seria atípica, muito menor do que aquela encontrada entre a maioria das populações esqueletais humanas, carecendo, portanto, de uma explanação específica.

Lund $(1842 ; 1844)$ foi o primeiro a tecer comentários sobre a morfologia dos esqueletos humanos por ele encontrados no Sumidouro. No que se refere ao tema deste artigo, é suficiente mencionar que Lund julgou existirem entre os cerca de 30 indivíduos, por ele exumados na gruta do Sumidouro, duas "raças" distintas. Chamou-lhe a atenção, principalmente, o fato de que alguns indivíduos possuíam uma testa extremamente fugidia, ao passo que outros apresentavam as bossas frontais mais verticalizadas.

O naturalista Reinhardt (1868), grande amigo de Lund, tendo-o visitado pelo menos uma vez em Lagoa Santa, foi o primeiro a descrever os fósseis humanos exumados por seu conterrâneo na gruta do Sumidouro. Seu principal objetivo no trabalho era, no entanto, o de avaliar criticamente a proposição de Lund quanto à contemporaneidade entre a megafauna e os esqueletos humanos daquela gruta. 
Revista de Antropologia, São Paulo, USP, 2004, v. 47 № 1.

Lacerda e Peixoto (1876) foram os primeiros antropólogos a desenvolverem uma análise crítica sobre os humanos exumados por Lund no Sumidouro. Tendo em vista que esses autores conduziram suas análises com base apenas no exemplar doado pelo naturalista dinamarquês ao Instituto Histórico e Geográfico do Rio de Janeiro, nada pôde ser expresso por estes pioneiros brasileiros sobre o grau de variabilidade desses paleoíndios. Duas grandes conclusões foram extraídas por Lacerda e Peixoto do estudo desse exemplar:

A sua extrema dolicocephalia induz-nos a suppôr que a raça primitiva do Brasil era dolicocéphala, e que só mais tarde a juxtaposição de outras raças emigradas para o solo brazileiro fez variar esse typo. (1876, p. 73). [E não menos importante que] As raças indígenas actuaes representam a mistura de dois typos differentes. (idem, p. 74)

Os dois especialistas do Museu Nacional do Rio de Janeiro inauguraram também a idéia de uma relação de ancestralidade-descendência direta entre os paleoíndios de Lagoa Santa e os índios Botocudos de Minas Gerais e Espírito Santo, relação esta rechaçada quase cem anos mais tarde por Mello e Alvim (1963), também por meio de estudos tipológicos. Cabe ressaltar que o artigo de Lacerda e Peixoto (1876), não obstante ter sido publicado em português, teve grande impacto na produção européia sobre a "raça de Lagoa Santa" que se seguiria.

Até onde sabemos, na Europa, Quatrefages (1879; 1881) foi o primeiro antropólogo físico a chamar a atenção dos especialistas para a importância dos achados de Lund. A partir das figuras publicadas por Lacerda e Peixoto (1876), aquele grande especialista europeu comparou a morfologia craniana do exemplar do Sumidouro, que ficou no Brasil, com outros crânios antigos da América e da Europa, não tendo, portanto, analisado pessoalmente um único exemplar da coleção Lund. 
W. A. Neves \& J. P. V. Atui. O mito da homogeneidade biológica...

Conseqüentemente não exprimiu qualquer opinião em seus trabalhos sobre o grau de diversidade dos paleoíndios do Sumidouro, o mesmo ocorrendo com Lütken (1884), que não era antropólogo.

Salvo engano de nossa parte, Kollman (1884) foi o primeiro antropólogo físico europeu a examinar, diretamente, alguns dos remanescentes ósseos humanos do Sumidouro enviados por Lund à Dinamarca. Tendo em vista que estudou quatro crânios completos e seis calotas do Sumidouro, ressaltou que "Erstens zeigt sie, dass diese 11 [Kollman adicionou às dez peças, por ele analisadas em Copenhague, os dados publicados por Peixoto e Lacerda, 1876] Individuen einer und derselben Rasse angehörten" (1884, p. 196) ${ }^{4}$, em oposição a Lund (1842; 1844), o qual havia sugerido a existência na coleção de duas raças distintas. Portanto, esse estudo internacional sobre os paleoíndios de Lagoa Santa destacou a homogeneidade biológica da série no sentido de identidade biológica comum.

Ten Kate (1885) foi o primeiro a analisar a quase totalidade dos crânios íntegros do Sumidouro da coleção dinamarquesa (14 exemplares passíveis de medições à época). Tendo em vista a braquicefalia do exemplar hoje conhecido por $\mathrm{SH}-17^{5}$, o autor tomou uma posição contrária a todos os que até então haviam encaminhado a favor de uma identidade biológica única no Sumidouro:

si M. Kollman avait examiné quinze crânes [Ten Kate agregou aos 14 crânios, estudados por ele pessoalmente, as medidas publicadas por Lacerda e Peixoto do crânio que ficou no Rio de Janeiro] au lieu de onze, il n'aurait pas dit que tous ces crânes on appartenu à dês individus d'une race parfaitment purê... (1885, p. 243) 
Revista de Antropologia, São Paulo, USP, 2004, v. 47 № 1.

Ele não deixou de reconhecer, entretanto, uma homogeneidade relativamente grande entre os esqueletos do Sumidouro quanto aos caracteres descritivos (morfoscópicos).

Ehrenreich (1887), em seu trabalho sobre as afinidades raciais dos Botocudos de Minas Gerais e Espírito Santo, expressou-se a favor de uma relação de descendência direta destes indígenas tardios com os antigos habitantes das grutas do centro mineiro, ratificando a idéia original de Lacerda e Peixoto (1876). Não emitiu, entretanto, qualquer juízo sobre o grau de variabilidade desses paleoíndios, ainda que aceitando, pelo menos implicitamente, uma identidade biológica única entre o material do Sumidouro.

Coube a Hansen (1888) efetuar o primeiro estudo completo dos remanescentes ósseos humanos exumados do Sumidouro por Lund. De acordo com ele, Reinhardt, Kollman e Ten Kate os haviam descrito apenas de maneira mais ou menos breve. Coube também a esse antropólogo dinamarquês atribuir uma numeração definitiva aos espécimes, numeração esta adotada em todos os estudos posteriores $(\mathrm{SH}-1$ a SH-17 sendo o exemplar SH-5 pertencente ao Instituto Histórico e Geográfico do Rio de Janeiro e o SH-8 pertencente ao Museu de História Natural de Londres). De acordo com Hansen:

Lês crânes fossiles de Lagoa Santa présentent à une seule exception près une uniformité remarquable (1888, p. 36), [agregando ainda que] lês quatorze (sic) crânes de Copenhague, lê crâne de Rio, et celui de Londres ont tous lê même aspect, ils sont très hauts, très alongue, la voûte cranienne est arroundie (1888, p. 36).

Da leitura destes dois parágrafos, depreende-se que Hansen também percebeu uma grande identidade biológica entre os exemplares do Sumidouro, mas é possível que as palavras "uniformité remarquable" 
W. A. Neves \& J. P. V. Atui. O mito da homogeneidade biológica...

queiram também transmitir a idéia de uma homogeneidade exacerbada entre os exemplares. Entretanto, a afirmação do autor que se segue aos dois parágrafos anteriores, que "L’uniformité de ces crânes vient à l'appui de la théorie (...) sur l'existence d'une race primitive" (p. 36), nos inclina a alinhá-lo aos demais autores europeus que utilizaram as palavras uniformidade e homogeneidade apenas no sentido de identidade "racial".

O melhor estudo comparativo da morfologia craniana dos antigos habitantes de Lagoa Santa com outras populações pré-históricas e etnográficas da América do Sul, no início do século XX, foi o efetuado por Rivet (1908). O autor tinha dois objetivos principais ao efetuar tal comparação: investigar se os esqueletos por ele exumados em Paltacalo no Equador tinham alguma relação com o "tipo paleoamericano", no qual incluía os esqueletos do Sumidouro e o esqueleto de Pontimelo ${ }^{8}$, da Argentina, e investigar, também, possíveis relações de ancestralidadedescendência entre várias tribos indígenas americanas atuais e os paleoamericanos. Suas análises confirmaram ambas as hipóteses. Quanto ao material do Sumidouro, à exceção do exemplar SH-17, concluiu, remetendo-se a Hansen (1888) que "Il ressort immédiatement de l'examen de ce graphique que lês crânes forment um groupement homogéne" (p. 215). Novamente, o resto do texto deixa claro que tal homogeneidade referiase, somente, ao grau de identidade, já que o objetivo de Rivet era tornar a "raça paleomaericana" um extrato universal no âmbito do Novo Mundo, extrato este ao qual outras levas migratórias mais recentes teriam se somado.

O estudo antropológico ainda mais influente até hoje realizado sobre os habitantes antigos de Lagoa Santa, apesar de baseado em fontes secundárias, é o de Hrdlicka no seminal Early Man in South América (1912). Hrdlicka, que se tornaria ainda em vida o mais eminente dos antropólogos físicos americanos, tendo fundado o American Journal of Physical Anthropology, periódico que ainda hoje dita as normas e as ten- 
dências na área, soube passar em revista, de maneira extremamente elegante e perspicaz, toda a literatura produzida até aquele momento sobre os crânios do Sumidouro, incluindo aí os próprios trabalhos originais de Lund. Seu texto é dedicado, na verdade, a solapar a hipótese de que os ossos humanos encontrados no Sumidouro eram contemporâneos aos ossos da megafauna ali também encontrados:

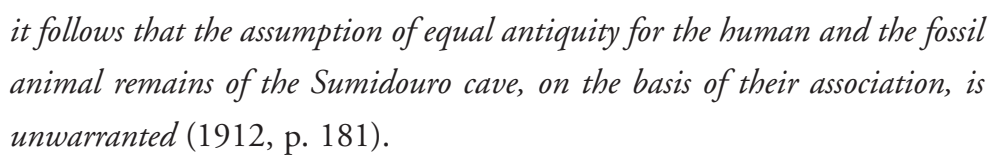

O trabalho foi inteiramente urdido no sentido de negar, peremptoriamente, uma ocupação humana pleistocênica na América do Sul e, por conseqüência, no Novo Mundo como um todo. Não tardaria muito para que restos da megafauna, inegavelmente abatida pelas lanças de Clovis, fossem encontrados na América do Norte (Figgins, 1927)!

Quanto à extrema dolicocefalia apresentada pelos crânios do Sumidouro, uma das características amplamente utilizadas por diversos antropólogos anteriores a Hrdlicka, Paul Rivet y comprís, para sugerir uma relação de ancestralidade com populações "negróides" da Melanésia, o eminente antropólogo americano também a minimizou: para ele os crânios de Lagoa Santa podiam ser perfeitamente incluídos entre os demais índios americanos dolicocéfalos, não carecendo de explicação especial:

and this type agrees in every point of importance with what may be considered the fundamental traits of the American race, more particularly in the dolichocephalic strain of that race. (1912, p. 183) 
W. A. Neves \& J. P. V. Atui. O mito da homogeneidade biológica...

Como para ele a "stem population", que teria dado origem a todos os grupos conhecidos de nativos americanos, era diversa desde sempre, nada é mencionado sobre uma eventual homogeneidade atípica entre a população de Lagoa Santa.

Eickstedt (1934), em seu trabalho seminal sobre as raças humanas americanas, discorreu longamente sobre os crânios do Sumidouro, mas baseado apenas em fontes secundárias, não tendo, portanto, emitido opinião sobre o grau de variabilidade dessa população.

Mais de duas décadas se passariam para que uma nova análise original sobre os crânios do Sumidouro fosse efetuada. Poech (1938), apesar de ter descrito, minuciosamente - região anatômica por região anatômica - cinco exemplares da coleção dinamarquesa, gastou grande parte de seus esforços descrevendo em detalhes dois fragmentos de frontais, cujos arcos supra-orbitais acentuados sugeriam a ela a presença no $\mathrm{Su}$ midouro de hominídeos ainda mais primitivos do que os representados pelo grosso dos espécimes íntegros. Quanto a estes últimos, Poech reconheceu entre eles duas "raças" distintas, tendo-as denominado de "raça botocuda" e "raça patagônica". Foi além, sugerindo que a diferenciação dessas duas raças se dava muito mais por características faciais que neurocranianas. Portanto, ainda que por razōes distintas a Ten Kate (1885), Poech (1938) voltou a enfatizar a insinuação original de Lund de que dois "tipos raciais" distintos estavam representados no material do Sumidouro, tomando, portanto, uma posição clara pela diversidade e não pela homogeneidade, mesmo que apenas no sentido de uniformidade "racial".

José Imbelloni, primeiro e provavelmente último antropólogo físico sul-americano no século XX, cujas idéias tiveram grande impacto no exterior, debruçou-se como poucos sobre a morfologia dos paleoíndios de Lagoa Santa e de outros materiais supostamente antigos do continente americano. Em sua "Tabla clasificatoria de los índios" (1938), seu 
trabalho geograficamente mais abrangente, já que cobria todo o Novo Mundo, o antropólogo argentino defendeu veementemente uma posição contrária à de Hrdlicka, o que por si só demandava grande coragem acadêmica na primeira metade do século XX (se não até hoje). Favoreceu a idéia de que as Américas tinham sido colonizadas por "raças" distintas, desde as mais primitivas, representadas pelos "Australóides", até as mais modernas, saídas do tronco "Xantodermo". Para ele, os crânios do Sumidouro, assim como outros de antiguidade paleoíndia, demonstravam a presença no Novo Mundo de uma morfologia "melanesóide", classificada por ele, no contexto americano, como "Láguidos". Junto aos "Fuéguidos" (representados entre outros pelos construtores de sambaquis do litoral sul do Brasil e pelos Botocudos), ainda mais antigos e primitivos, os lácidas formariam "la estratificación más primitiva de las poblaciones de América" (1938, p. 242-3). Imbelloni não omitiu qualquer juízo sobre algum eventual grau atípico de homogeneidade biológica entre os crânios de Sumidouro, vis-à-vis as demais populações por ele examinadas nas três Américas.

Coube a Bastos d'Ávila (1950) elaborar o segundo trabalho bioantropológico brasileiro sobre os habitantes antigos de Lagoa Santa com impacto internacional, já que sua contribuição fez parte do seminal Handbook of South American Indians, editado por Julian Steward, o pai da ecologia cultural. Na verdade, como já denuncia o título de sua contribuição àquela obra seminal, "Anthropometry of the Indians of Brazil", o proeminente antropólogo físico brasileiro esforçou-se para apresentar um quadro o mais abrangente e sintético possível sobre a variabilidade morfológica, esqueletal e corporal dos índios brasileiros, pré-históricos e atuais. Adotando a influente terminologia de Imbelloni, Bastos d'Ávila aceitava a classificação dos crânios de Lagoa Santa, agora não mais restritos apenas aos do Sumidouro, como parte dos "Lácidas" - "thought to have been the first inhabitants of Brazil and perhaps of 
W. A. Neves \& J. P. V. Atui. O mito da homogeneidade biológica...

South América" (1950, p. 73). Ele acreditava também que grande parte dos Lácidas foi substituída ou absorvida biologicamente por levas posteriores que dominaram os primeiros habitantes. Para ele, os Nambikuara poderiam representar, potencialmente, uma sobrevivência dos Lácidas em território brasileiro", tendo em vista que eles "have generally very low foreheads, probably chamecephalic, thus approximating the Australoid type" (idem, p. 76). Nada é mencionado por Bastos d'Ávila (1950) em sua revisão sobre o grau de diversidade biológica dos habitantes antigos de Lagoa Santa.

Messias e Mello e Alvim (1962), sobretudo estimulados pelas novas descobertas de vários esqueletos humanos no maciço de Cerca Grande, pela missão norte-americana, durante os anos 1950 (Hurt \& Blasi, 1969), esqueletos estes que se somaram à já expressiva coleção craniana de Lagoa Santa do Museu Nacional do Rio de Janeiro, concluíram que a série "represents an homogeneous population with distinctive physical characteristics" (idem, p. 40), dando a impressão de que também nesse trabalho a palavra homogeneidade foi empregada apenas no sentido de uma única identidade biológica.

Salvo engano de nossa parte, foi Mello e Alvim (1977) que, primeiramente, pelo menos de forma explícita, agregou ao termo homogeneidade biológica, no contexto dos primeiros habitantes de Lagoa Santa, a idéia de uma variabilidade atipicamente reduzida. Ainda que de cunho descritivo e tipológico, mesmo que elaborado em plena década de 1970, o trabalho de Mello e Alvim (idem) continua o estudo bioantropológico mais amplo até o momento conduzido sobre os remanescentes ósseos humanos antigos de Lagoa Santa depositados em instituições brasileiras. Partindo da análise de 108 crânios, sendo 30 deles representados apenas por mandíbulas, a autora, no rastro de seus antecessores, concluiu que: 
Revista de Antropologia, São Paulo, USP, 2004, v. 47 no 1.

o estudo comparativo desses conjuntos comprovou não existirem diferenças expressivas entre eles, demonstrando que devem ser considerados como pertencentes a uma mesma população. (1977, p. 134)

Entretanto, além de reconhecer uma única unidade antropofísica em Lagoa Santa, Mello e Alvim (1977), sem nenhuma demonstração formal aparente ${ }^{10}$, afirmou que "o material ósseo humano aqui analisado restos esqueletais de 180 a 200 indivíduos - apresenta um somatório de elementos morfológicos comuns, capaz de caracterizá-lo como pertencente a uma população muito homogênea" (idem, p. 159; grifo nosso), tendo inaugurado, portanto, a imagem de uma população atipicamente pouco diversa, vis-à-vis outras populaçōes humanas. Nesse sentido, o novo significado emprestado por Mello e Alvim (1977) à palavra homogeneidade carecia de uma explanação especial. Para ela "o 'grupo de fundadores' ter-se-ia constituído num isolado, com forte grau de endocruzamento, através de confinamento genético" (idem, p. 157). O confinamento genético imaginado por Mello e Alvim teria envolvido, entre outros fatores, "confinamento geográfico" (idem, p. 161).

Complementando sua análise morfométrica e morfoscópica dos homens antigos de Lagoa Santa, Mello e Alvim et al. (1983-1984) passaram em revista, entre outros materiais, 491 espécimes daqueles paleoíndios sob o aspecto da variação não-métrica craniana, conceito metodológico este introduzido no Brasil por um de nós (Neves, 1980). Para aqueles autores, a distribuição das freqüências de 65 caracteres não-métricos cranianos também demonstrou uma maior homogeneidade biológica entre os paleoíndios de Lagoa Santa do que entre os construtores de sambaquis, ocupando os índios Botocudos posição intermediária neste contínuo de variação. Mello e Alvim et al. (1983-1984) viram nesses resultados uma confirmação daquilo que já havia emergido da análise de caracteres craniométricos e cranioscópicos efetuados nos anos 1970. 
W. A. Neves \& J. P. V. Atui. O mito da homogeneidade biológica...

A demonstração formal apresentada por Mello e Alvim et al. (19831984), para avaliar o grau de variabilidade intrapopulacional das três populações esqueletais por eles estudadas do ponto de vista da variação não-métrica craniana, baseou-se no número absoluto de caracteres com freqüência zero em cada população (27 no caso de Lagoa Santa, 22 no caso dos Botocudos e 19 no caso dos construtores de sambaquis do sul do Brasil), raciocínio quantitativo inaceitável como demonstraremos nos próximos parágrafos.

De fato, quando se trata de características biológicas que se expressam apenas como "presença" ou "ausência" (caracteres discretos, do ponto de vista estatístico, uma vez que não apresentam valores contínuos entre zero e um), uma população será tanto mais diversa quanto mais a freqüência média entre todos os traços analisados tender a 0,5 (ou 50\%). Dito de outra forma, quando $50 \%$ dos indivíduos analisados apresentam o traço, enquanto os outros $50 \%$ não o apresentam, mais diversa é uma população biológica para aquele traço (Lewontin, 1974).

Em suma, quando uma determinada população (ou amostra representativa de uma população) apresenta muitos traços discretos fixados nos extremos 0 e 100\%, maior a possibilidade de se tratar de fato de uma população que tende à homogeneidade. Mas não se pode nesse raciocínio desprezar as freqüências intermediárias (entre 0 e 1 ) dos demais traços, que compõem o conjunto da lista dos caracteres sob análise, nem muito menos ignorar se as diferenças absolutas interpopulacionais de "ausências totais" ou de "presenças totais" encontradas são significativas ou não, do ponto de vista estatístico.

Nesse sentido, a demonstração formal apresentada por Mello e Alvim (1977), para propor uma hierarquia de grau de homogeneidade biológica entre paleoíndios de Lagoa Santa, índios Botocudos e construtores de sambaquis, não se sustenta quando examinada sob os dois critérios acima mencionados. Primeiramente, não há qualquer nível de signi- 
ficância estatística aceitável ${ }^{11}$ para sustentar que as diferenças entre as fraçôes 27/65 (Lagoa Santa), 22/65 (Botocudos) e 19/65 (Sambaquis) merecem ser utilizadas para alavancar qualquer raciocínio suplementar. Em outras palavras, de um ponto de vista quantitativo formal, essas freqüências (de caracteres fixados em $0 \%$ nas três populaçōes analisadas) são iguais. Em segundo lugar, quando a freqüência média entre os 65 traços analisados é calculada, chega-se aos seguintes valores: 0,1333 para Lagoa Santa; 0,1315 para Botocudos; e 0,1859 para Sambaquis. As diferenças entre esses valores são desprezíveis e não-significativas estatisticamente, mostrando que as três séries analisadas apresentam graus de homogeneidade/heterogeneidade biológica muito semelhantes, variando entre $13 \%$ e $18 \%$.

Soto-Heim (1994), responsável pelo último estudo descritivo da coleção de Copenhague, apesar de também ter salientado uma certa homogeneidade entre os esqueletos do Sumidouro (aos quais ela adicionou um esqueleto oriundo de Escrivânia III $^{12}$, também coletado por Lund, material este nunca mencionado anteriormente pelos muitos especialistas que se dedicaram àquela coleção), parece tê-lo feito no mesmo sentido empregado pelos especialistas que estudaram estes paleoíndios anteriormente aos anos 1970:

Lês observations et mesures que nous avons effectuées sur lês crânes de Lagoa Santa (...) confiment l'existence d'une certaine homogeneité que traduisent um ensemble de disposions communes plus ou moins pronouncées selon lês sujets, quel que soit lê sexe. (1994, p. 90) 
W. A. Neves \& J. P. V. Atui. O mito da homogeneidade biológica...

\section{A apropriação do mito}

A suposta homogeneidade biológica atípica dos primeiros habitantes da região de Lagoa Santa, preconizada por Mello e Alvim (1977) e ratificada por Mello e Alvim et al. (1983-1984), sem qualquer demonstração formal aceitável, foi rapidamente assimilada pelos arqueólogos e préhistoriadores brasileiros que direta ou indiretamente trataram destes paleoíndios.

Apenas um ano após a proposta ter sido publicada, Prous já elaborava que:

D'une manière générale, on a l'impression que lês populations vivaient au précerâmique [em Lagoa Santa] dans um territoire fermé, bien adaptées au milieu karstique, et étaient marquée par un certain immobilisme culturel. L'homogénéité du type physique renforce cette idée. (1978, p. 75; grifo nosso)

Não obstante o mesmo autor, na mesma publicação, ter demonstrado que matérias-primas líticas eram trocadas pela população local com grupos distantes até mesmo 200 quilômetros de Lagoa Santa.

Schmitz (1984), responsável pela primeira síntese moderna sobre caçadores coletores pré-históricos do Brasil, também aderiu à idéia de uma homogeneidade biológica atípica em Lagoa Santa, tendo enfatizado que "segundo Alvim e outros, na confirmação de sua grande homogeneidade morfológica no tempo", adotando também a idéia de um grupo fundador pequeno que se tornou isolado, para explicá-la. Schmitz (idem), entretanto, não utilizou em qualquer momento em sua síntese tal informação para elaborar aspectos da organização social desses grupos.

Foi, contudo, no primeiro livro-síntese sobre a pré-história brasileira que Prous levou, para um público mais amplo, a idéia preconizada por Mello e Alvim (1977) e Mello e Alvim et al. (1983-1984) de um baixo 
Revista de Antropologia, São Paulo, USP, 2004, v. 47 no 1.

grau de diversidade intrapopulacional em Lagoa Santa, agora não somente baseada em caracteres métricos, mas também em caracteres não-métricos:

A raça de Lagoa Santa é caracterizada por sua grande homogeneidade, tanto nas característica morfométricas (...) quanto nas particularidades epigenéticas (1991, p. 193) (...) o alto grau de homogeneidade da população e a difusão dos caracteres epigenéticos apontam para uma forte endogamia, seja pela ausência de populaçôes vizinhas, seja pela instituição de casamentos preferencias, por exemplo entre primos cruzados. (p. 194; grifo nosso)

No exterior, a disseminação desse quadro sobre a população paleoíndia de Lagoa Santa para o público leigo, mas interessado em ciência, foi efetuada por Prous:

La très étroite ressemblance entre lês individus (...) suggère que cette population formait un isolat génétique et que sés membres etaient donc tous apparentés à dês dregés divers. (1990)

Prous e Fogaça também fizeram questão de salientar a grande homogeneidade biológica dos paleoíndios de Lagoa Santa numa revisão recente sobre a pré-história brasileira do final do Pleistoceno e início do Holoceno, publicada no exterior para o público especializado. Nas palavras dos autores:

the Lagoa Santa type is very homogeneous and shows characteristics features (...) also attest a great homogeneity suggesting genetic isolation. (1999, p. 27) 
W. A. Neves \& J. P. V. Atui. O mito da homogeneidade biológica...

\section{A desconstrução do mito: à guisa de "material e métodos"}

O material incluído neste trabalho refere-se a 73 crânios humanos adultos em diversos estados de conservação, exumados de grutas e abrigos da região arqueológica de Lagoa Santa, entre 1842 e 1975. A Tabela I fornece a identificação desses crânios quanto às coleções das quais fazem parte, às instituições onde estão depositados, ao sexo dos indivíduos, aos sítios arqueológicos de onde provêm (à exceção da coleção Harold Walter), e aos responsáveis pelas escavações desses sítios. À exceção dos espécimes de Santana do Riacho e dos espécimes do Sumidouro, todos os demais crânios fizeram parte dos estudos de Mello e Alvim (1977) e Mello e Alvim et al. (1983-1984).

Do ponto de vista cronológico, pode-se dizer que os indivíduos incluídos neste trabalho estão inseridos numa faixa cronológica entre aproximadamente 11 e 8 mil anos antes do presente ${ }^{13}$, e a maioria está compreendida entre 8,5 e 8 mil anos. Conforme recentemente enfatizado por Araújo et al. (2002), o pico do uso dos abrigos sob-rocha como cemitérios na região de Lagoa Santa ocorreu nesse intervalo, e os esqueletos humanos mais antigos que 8,5 mil anos - na verdade apenas dois, Luzia, exumada da Lapa Vermelha IV, e o Homem de Confins, exumado por Harold Walter e colaboradores, da câmara interna da Lapa Mortuária de Confins - referem-se a indivíduos isolados que não foram enterrados formalmente, mas apenas depositados em posição estendida, na superfície do solo, em locais naturalmente protegidos.

Os 73 crânios foram medidos por um mesmo bioantropólogo (WAN) para evitar erro interobservador. As medidas craniométricas tomadas seguiram o protocolo de Howells (1973) para facilitar a comparação com outros grupos humanos do planeta.

A Tabela II apresenta as 50 medidas tomadas, separadas em dois conjuntos - medidas faciais e medidas neurocranianas. Tendo em vista que 
Revista de Antropologia, São Paulo, USP, 2004, v. 47 № 1.

o protocolo de Howells (1973) é no momento o mais utilizado internacionalmente, sua nomenclatura original em inglês foi mantida.

Como séries comparativas foram utilizadas as 30 amostras de crânios humanos estudadas por Howells (1973; 1989; 1995), às quais foram acrescentadas duas séries de grupos costeiros do litoral central de Santa Catarina (Tapera e Base Aérea), medidas, no início dos anos 1980, por Mya Pereira da Silva (Musée de L'Homme, Paris) e por um dos autores (WAN), e a série Pericús, um grupo indígena isolado por milhares de anos na Baja California, dizimado no século XVI com a chegada dos primeiros espanhóis, que foram estudados recentemente por GonzálezJosé et al. (2003).

A Tabela III apresenta as séries comparativas usadas bem como a procedência geográfica de cada uma delas.

Cabe salientar que as séries estudadas por W. W. Howells são também séries regionais, prestando-se, portanto, perfeitamente, como parâmetros comparativos, em termos de variabilidade intrapopulacional, contra os quais a variabilidade da população antiga de Lagoa Santa pode ser comparada.

A estatística principal utilizada para aferir o grau de variabilidade intrapopulacional, tanto em Lagoa Santa quanto nas séries comparativas, foi o coeficiente de variabilidade (CV), que nada mais é do que a divisão do desvio-padrão pela média de cada amostra para cada variável craniométrica. Como forma de sintetizar a variabilidade a partir do conjunto total de variáveis craniométricas estudadas, foi produzido um Coeficiente de Variabilidade médio para cada série, levando-se em consideração as 50 variáveis métricas utilizadas. Todos os cálculos foram efetuados para as parcelas masculina e feminina de cada série separadamente. Tendo em vista que o número de variáveis métricas, tomadas por Gonzaléz-José et al. (2003) na série Pericús, foi menor do que aquele tomado nas demais séries aqui estudadas, um segundo cálculo de CVs 
W. A. Neves \& J. P. V. Atui. O mito da homogeneidade biológica...

foi efetuado sobre apenas 27 variáveis para permitir uma comparação com uma população sabidamente isolada.

Tendo em vista que a série Lagoa Santa apresenta um N médio bastante inferior ao da maioria das séries comparativas, uma vez que por se tratar de material antigo dificilmente os crânios se conservam íntegros, dois testes foram realizados para verificar se os valores dos coeficientes de variabilidade gerados poderiam ser significativamente afetados por tamanho amostral.

O primeiro teste consistiu no cálculo do coeficiente de correlação de Pearson entre tamanho amostral efetivo e variabilidade para as séries Howells, tamanhos estes que variam entre 10 e 58 (Lagoa Santa apresenta um tamanho de 17 , no caso dos homens, e de 15 , no caso das mulheres). Tanto no caso dos homens $(\mathrm{r}=0,060 ; \mathrm{p}>0,05)$, quanto no caso das mulheres $(r=-0,280 ; p>0,05)$, as correlações não se mostraram significativas, afastando, em princípio, a possibilidade de que o pequeno tamanho amostral efetivo de Lagoa Santa pudesse impactar seu coeficiente de variação médio.

Como medida de precaução, o mesmo problema foi atacado de maneira alternativa, por bootstrap (Efron, 1979). Primeiramente foram selecionadas, entre as 30 séries comparativas de Howells, 11 séries representando as principais regióes do planeta. Para cada uma dessas 11 séries, foram produzidas artificialmente cem subséries sorteando-se aleatoriamente 17 homens e 15 mulheres. Novos coeficientes médios de variação foram calculados para cada uma dessas novas subséries aleatoriamente constituídas, comparando-se os resultados assim obtidos com o coeficiente de variação original das 11 séries Howells selecionadas para o teste.

A Tabela IV apresenta os resultados obtidos a partir do bootstrap. Conforme pode ser verificado, os coeficientes originais de variação são minimamente afetados por uma redução drástica do tamanho amostral. 
Revista de Antropologia, São Paulo, USP, 2004, v. 47 № 1.

Outra tendência que pode ser verificada na Tabela IV é que nos $22 \mathrm{ca}-$ sos os coeficientes de variação médios tendem a diminuir ligeiramente quando o tamanho amostral efetivo é diminuído.

Ambos os testes deixam claro que, em termos de tamanho amostral, a série Lagoa Santa pode ser perfeitamente comparada às séries de referência quanto ao cálculo do coeficiente de variabilidade. Embora o pequeno tamanho efetivo da série paleoíndia seja bem menor do que o das séries comparativas Howells, esta discrepância não é suficiente para impactar significativamente qualquer comparação entre seus CVs médios. O coeficiente de variação de Lagoa Santa pode, entretanto, ter sido ligeiramente subestimado, de forma não significativa, mas jamais superestimado.

\section{Resultados}

As Tabelas V e VI mostram os coeficientes de variação médios das 33 principais séries incluídas no trabalho (30 oriundas do banco de dados de W. W. Howells, duas do litoral sul do Brasil e uma de Lagoa Santa). No caso dos homens, a variação planetária vai de 6,26\%, entre os Maori do Norte, e 8,49\%, entre os Bosquímanos. No caso das mulheres, a variação planetária oscila entre 6,43\% (Aborígenes Australianos) e 9,22\% (Base Aérea). Conforme pode ser verificado, sobretudo pela análise da Figura 1, a população paleoíndia de Lagoa Santa não só apresenta altíssima variação morfológica $(8,35 \%$, entre os homens, e $9,09 \%$, entre as mulheres), como está entre as populações que hoje apresentam, no planeta, as maiores variações morfológicas, ou seja, as populações africanas subsaarianas (Howells, 1973; 1989; 1995; Relethford \& Blangero, 1990; Sarich, 1999). 
W. A. Neves \& J. P. V. Atui. O mito da homogeneidade biológica...

Quando comparada às duas amostras do litoral sul do Brasil, Lagoa Santa é bastante semelhante a ambas em termos de variabilidade, tanto no caso dos homens quanto no caso das mulheres. Portanto, nem mesmo quando comparada apenas a outras populaçōes pré-históricas brasileiras, estas também estudadas amplamente por Mello e Alvim e colaboradores (Mello e Alvim \& Mello Filho, 1965; 1967-1968; Mello e Alvim \& Uchoa, 1976; 1980), seria lícito inferir que a população paleoíndia de Lagoa Santa apresenta grau elevado de homogeneidade biológica.

Quando comparada à série Pericús da Baja California (BCS) (Tabelas VII e VIII), uma das populações mais homogêneas representadas neste trabalho, sabidamente isolada, salta aos olhos que a população paleoíndia de Lagoa Santa se comporta de forma diametralmente oposta ao que deveria em termos de variabilidade intrapopulacional se tivesse sido submetida a processos de isolamento geográfico e genético, como desejava Mello e Alvim (1977) e Mello e Alvim et al. (1983-1984).

\section{Conclusões e considerações finais}

Neste trabalho nos propusemos avaliar, por meio de testes estatísticos simples, a variabilidade morfológica da população paleoíndia de Lagoa Santa, vis-à-vis a variabilidade morfológica humana planetária atual. Nossos resultados não deixam dúvidas de que esses primeiros ocupantes do território sul-americano, de morfologia paleoamericana, apresentavam altíssima variabilidade intrapopulacional, como de resto, a esmagadora maioria das populações humanas até hoje estudadas ${ }^{14}$.

Nossos resultados fazem sentido também à luz da literatura antropológica atual e da literatura genético-populacional clássica. Sewal Wright (1931; 1943) foi o primeiro a mostrar que mesmo taxas muito baixas 
Revista de Antropologia, São Paulo, USP, 2004, v. 47 № 1.

de fluxo gênico entre duas populaçôes biológicas podem alterar significativamente suas freqüências gênicas (a migração de apenas um indivíduo a cada geração, entre duas populaçōes biológicas, é o suficiente para torná-las semelhantes geneticamente).

O mesmo assunto foi recentemente revisitado por Templeton (1993), no contexto da discussão sobre os dois modelos preponderantes a respeito da origem do homem moderno no planeta (Modelo Multiregional versus Modelo da Monogênese Africana). As modelagens de Templeton apresentaram que traços morfológicos neutros ou seletivamente benéficos, que porventura aparecessem em um extremo do planeta, poderiam rapidamente ter se espalhado para outros extremos do Velho Mundo, mesmo considerando a baixa demografia dos hominídeos que imediatamente nos precederam.

Em resumo, do ponto de vista da genética-populacional clássica e atual, razões extremamente específicas e agudas são necessárias para que uma população biológica (incluindo as humanas) sofra perda significativa de variabilidade (Relethford \& Harpending, 1995; para um exemplo catastrófico há cerca de 70 mil anos, ver Ambrose, 1998). O único cenário possível de ocasionar perda significativa de variabilidade entre os humanos é a justaposição entre grandes catástrofes planetárias, seguidas de isolamento reprodutivo completo por parte de pequenas populações locais, seja por barreiras geográficas intransponíveis, seja pela extinção total de outras populações coespecíficas - o caso da explosão do vulcão Toba na Indonésia há 70 mil anos que produziu um "inverno nuclear" de cerca de cinco anos em todo o Velho Mundo, conforme Ambrose (1998).

O conhecimento atual sobre a evolução social humana (leia-se complexificação social) do final do Pleistoceno até o Holoceno tardio tem mostrado que, pelo menos no Velho Mundo, houve uma pequena diminuição da variabilidade biológica humana ao longo do tempo, fazendo 
W. A. Neves \& J. P. V. Atui. O mito da homogeneidade biológica...

com que necessariamente populações humanas do final do Pleistoceno apresentem mais variação morfológica do que as tardias ou atuais (Van Vark et al., 2003). Com o advento da domesticação de plantas e animais, sociedades mais densas demograficamente e mais complexas socialmente passaram ao longo de nossa história sub-recente a exercer forte poder de expansão e assimilação de populações menores e mais simples tecnologicamente.

Esse fenômeno tomou grandes proporções com o aparecimento dos primeiros estados expansionistas que, ao expandirem seu poder, também espalharam seus genes por grandes extensões de terra, produzindo, assim, uma certa homogeneização nos seus territórios de domínio. Por essa ótica, dificilmente populações humanas do final do Pleistoceno e início do Holoceno, sobretudo no Hemisfério Ocidental, poderiam apresentar pouca variabilidade morfológica. Em outras palavras, a densidade demográfica, a mobilidade, os sistemas de assentamento e de captação de recursos, bem como outras características das sociedades caçadoras-coletoras (leiam-se sistemas e regras de casamento e residência pósmarital) favorecem a diversidade biológica, conforme muito bem reconheceram Mello e Alvim e Souza:

Os modernos estudos em tribos relativamente isoladas demonstram que, via de regra, nesses grupos não há oscilações genéticas muito acentuadas entre subgrupos de uma mesma tribo ou entre bandos vizinhos e afins, a não ser excepcionalmente e por curto período de tempo, uma vez que a maior parte delas está sujeita ao processo de fissão-fusão que mantém a redistribuição das freqüências gênicas. (1990, p. 72)

Tampouco há no registro geográfico e paleoambiental qualquer informação que possa favorecer a hipótese de que os antigos habitantes de Lagoa Santa estivessem isolados. Como já é de domínio pleno, mesmo 
que o final do Pleistoceno no Brasil Central tenha se caracterizado por climas mais frios e mais secos que os atuais (Behling, 1998), é certo que nenhuma grande barreira intransponível ao deslocamento humano poderia ter isolado os habitantes de Lagoa Santa de populações próximas e adjacentes. O Brasil Central estava, sabidamente, vastamente ocupado entre aproximadamente 11 e 8 mil anos atrás (Schmitz, 1984; Prous \& Fogaça, 1999).

Do ponto de vista bioantropológico, os paleoíndios de Lagoa Santa não se configuram uma população biológica com traços morfológicos derivados exclusivos, que poderiam apontar para algum tipo de singularidade causada por isolamento. Mello e Avim (1992-1993) demonstrou, ainda que por métodos raciológicos, que a mesma população estava presente na Serra do Cipó, cerca de 60 quilômetros ao norte de Lagoa Santa. Mais recentemente, além de comprovar por métodos quantitativos que os antigos habitantes de Santana do Riacho I de fato apresentam a mesma morfologia craniana paleoamericana presente em Lagoa Santa (Neves et al., 2003), esta mesma morfologia foi detectada na Bahia (Hubbe et al, submetido), em São Paulo (Neves et al., submetido), no sul do Chile (Neves et al., 1999a), na Colômbia (Munford \& Neves 1994), no México (González-José et al., no prelo) e na Flórida (Powell et al., 1999), não deixando a menor dúvida de que esses paleoamericanos ocuparam vastamente e de forma geograficamente contínua o novo Mundo, como desejavam Rivet (1908) e Imbelloni (1938).

Em síntese, de qualquer ângulo que se analise, a proposta de que os primeiros habitantes da região arqueológica de Lagoa Santa constituíam uma população isolada, extremamente homogênea do ponto de vista biológico, não pode ser aceita com a empiria disponível, no passado e no presente. 
W. A. Neves \& J. P. V. Atui. O mito da homogeneidade biológica...

\section{Tabela I}

Número de referência, sítio de origem, identificação do coletor, sexo e instituição dos crânios utilizados no presente estudo

\begin{tabular}{|c|c|c|c|c|c|}
\hline & Masculinos & & & Femininos & \\
\hline Referência & & & Referência & & \\
\hline instituciona & Sítio & Coletor & institucional & Sítio & Coletor \\
\hline CONFINS & - & Harold Walter & HW 001 & - & Harold Walter \\
\hline HW 002 & - & Harold Walter & HW 003 & - & Harold Walter \\
\hline HW 009 & - & Harold Walter & HW 004 & - & Harold Walter \\
\hline HW 010 & - & Harold Walter & HW 005 & - & Harold Walter \\
\hline HW 013 & - & Harold Walter & HW 006 & - & Harold Walter \\
\hline HW 014 & - & Harold Walter & HW 016 & - & Harold Walter \\
\hline HW 017 & - & Harold Walter & HW 018 & - & Harold Walter \\
\hline HW 019 & - & Harold Walter & HW 020 & - & Harold Walter \\
\hline HW 025 & - & Harold Walter & HW 021 & - & Harold Walter \\
\hline HW 027 & - & Harold Walter & HW 029 & - & Harold Walter \\
\hline HW 030 & - & Harold Walter & Lund-2302 & Escrivania 3 & Lund \\
\hline MN 1319 & Cerca Grande 5 & Hurt \& Blasi & MN 1325 & Cerca Grande 6 & Hurt \& Blasi \\
\hline MN 1332 & Cerca Grande 2 & Hurt \& Blasi & MN 1353 & Cerca Grande 6 & Hurt \& Blasi \\
\hline MN 1334 & Cerca Grande 5 & Hurt \& Blasi & MN 1383 & Cerca Grande 6 & Hurt \& Blasi \\
\hline MN 1355 & Cerca Grande 6 & Hurt \& Blasi & MN 1388 & Cerca Grande 7 & Hurt \& Blasi \\
\hline MN 1357 & Cerca Grande 6 & Hurt \& Blasi & MN 1959 & Lapa Vermelha IV & Emperaire \\
\hline MN 805 & Lapa Mortuária & Padberg & MN 806 & Lapa Mortuária & Padberg \\
\hline MN 807 & Lapa Mortuária & Padberg & MN 809 & Lapa D'água & Padberg \\
\hline MN 907 & Lapa da Amoreira & Padberg & MN 812 & Lapa Mortuária & Padberg \\
\hline SR1-1 & Santana do Riacho 1 & Prous & SR1-2 & Santana do Riacho 1 & Prous \\
\hline SR1-4 & Santana do Riacho 1 & Prous & SR1-3 & Santana do Riacho 1 & Prous \\
\hline SH-01 & Sumidouro & Lund & SR1-5 & Santana do Riacho 1 & Prous \\
\hline SH-02 & Sumidouro & Lund & SR1-6 & Santana do Riacho 1 & Prous \\
\hline
\end{tabular}


Revista de Antropologia, São Paulo, USP, 2004, v. 47 no 1.

\begin{tabular}{llllll} 
SH-03 & Sumidouro & Lund & SH-06 & Sumidouro & Lund \\
SH-04 & Sumidouro & Lund & SH-07 & Sumidouro & Lund \\
SH-05 & Sumidouro & Lund & SH-08 & Sumidouro & Lund \\
SH-09 & Sumidouro & Lund & SH-10 & Sumidouro & Lund \\
SH-11 & Sumidouro & Lund & SH-14 & Sumidouro & Lund \\
SH-13 & Sumidouro & Lund & SH-15 & Sumidouro & Lund \\
SH-16 & Sumidouro & Lund & SH-17 & Sumidouro & Lund \\
WN-01 & Sumidouro & Lund & WN-02 & Sumidouro & Lund \\
WN-04 & Sumidouro & Lund & WN-03 & Sumidouro & Lund \\
WN-05 & Sumidouro & Lund & WN-07 & Sumidouro & Lund \\
WN-06 & Sumidouro & Lund & WN-09 & Sumidouro & Lund \\
WN-08 & Sumidouro & Lund & WN-12 & Sumidouro & Lund \\
WN-10 & Sumidouro & Lund & WN-13 & Sumidouro & Lund \\
WN-11 & Sumidouro & Lund & & & \\
& & & & \\
\hline
\end{tabular}

\section{Instituições}

As referências institucionais iniciadas por:

MN Museu Nacional/Universidade Federal do Rio de Janeiro;

$\mathrm{SH}, \mathrm{WN}$ e Zoological Museum/University of Copenhage, excetuando-se

Lund-2302 SH-05 do Instituto Histórico e Geográfico Brasileiro/Rio de Janeiro e SH-08 do Natural History Museum of London;

HW, SR1

e CONFINS Museu de História Natural/Universidade Federal de Minas Gerais. 
W. A. Neves \& J. P. V. Atui. O mito da homogeneidade biológica...

\section{Tabela II}

Medidas craniométricas utilizadas no trabalho, mantida a nomenclatura original de Howells (1973)

\begin{tabular}{|c|c|c|c|}
\hline Medidas faciais & Total 30 & Medidas neurocranianas & Total 20 \\
\hline Basion-prosthion length & BPL & Basion-bregma height & $\mathrm{BBH}$ \\
\hline Bifrontal breadth & FMB & Basion-nasion length & $\mathrm{BNL}$ \\
\hline Bijugal breadth & JUB & Biasterionic breadth & ASB \\
\hline Bimaxillary breadth & ZMB & Biauricular breadth & AUB \\
\hline Biorbital breadth & EKB & Bregma-subtense fraction & PAF \\
\hline Bizygomatic breadth & ZYB & Foramen magnum length & FOL \\
\hline Cheek height & WMH & Frontal cord & FRC \\
\hline Dacryon radius & DKR & Frontal subtense & FRS \\
\hline Dacryon subtense & DKS & Glabella projection & GLS \\
\hline Ectoconchion radius & EKR & Glabello-occipital length & GOL \\
\hline Frontalmalare radius & FMR & Lambda-subtense fraction & OCF \\
\hline Interorbital breadth & $\mathrm{DKB}$ & Maximum cranial breadth & ХCB \\
\hline Malar lenght, maximum & XML & Maximum frontal breadth & XFB \\
\hline Malar length, inferior & IML & Nasion-subtense fraction & FRF \\
\hline Malar subtense & MLS & Nasio-occipital length & NOL \\
\hline Molar alveolus radius & AVR & Occipital cord & OCC \\
\hline Nasal breadth & NLB & Occipital subtense & OCS \\
\hline Nasal height & $\mathrm{NLH}$ & Parietal cord & PAC \\
\hline Nasio-frontal subtense & NAS & Parietal subtense & PAS \\
\hline Nasion radius & NAR & Supraorbital projection & SOS \\
\hline Nasion-prosthion height & $\mathrm{NPH}$ & & \\
\hline Orbit breadth & OBB & & \\
\hline Orbit height & $\mathrm{OBH}$ & & \\
\hline
\end{tabular}


Revista de Antropologia, São Paulo, USP, 2004, v. 47 no 1.

\begin{tabular}{ll} 
Palate breadth, external & MAB \\
Prosthion radius & PRR \\
Simotic cord & WNB \\
Subspinale radius & SSR \\
Zygomaxillare radius & ZMR \\
Zygomaxillary subtense & SSS \\
Zygoorbitale radius & ZOR \\
\hline
\end{tabular}

Tabela III

Distribuição geográfica das séries comparativas

\begin{tabular}{lll}
\hline Série & Sigla & Localização geográfica \\
\hline Lagoa Santa & LST & Lagoa Santa - Minas Gerais - Brasil (Paleoíndios) \\
Tapera & TAP & Ilha de Santa Catarina - Santa Catarina - sul do Brasil (Sambaquieiros) \\
Base Aérea & BAS & Ilha de Santa Catarina - Santa Catarina - Brasil (Sambaquieiros) \\
Baja California & BCS & Califórnia - EUA (Pericús) \\
Teita & TEI & Sudeste do Kenya - Leste da África (Bantos Teita) \\
Dogon & DOG & Planalto de Bandiagara - Mali - Oeste Africano (Dogons ou Tellems) \\
Zulu & ZUL & África do Sul - África (Bantos Zulus) \\
Bushman & BUS & Província do Cabo - África do Sul (San ou Bosquímanos "pré-Bantos") \\
Egito & EGY & Gizeh - Egito - Norte Africano (Egípcios) \\
Norse & NOR & Oslo - Noruega - Norte Europeu \\
Zalavar & ZAL & Costa Oeste do Lago Balaton - Hungria -Europa Central (Zálavar) \\
Berg & BER & Greifenburg - Áustria - Europa Central (Berg) \\
Mokapu & MOK & Costa norte da península Mokapu - Havaí - \\
& & Polinésia (Mokapu, Oahu, Havaí) \\
Ilha da Páscoa & EAS & Ilha da Páscoa - Polinésia - Pacífico Sul
\end{tabular}


W. A. Neves \& J. P. V. Atui. O mito da homogeneidade biológica...

$\begin{array}{lll}\text { Moriori } & \text { MOR } & \text { Ilhas Chatam - Pacífico Sul } \\ \text { Japão Norte } & \text { NJA } & \text { Hokkaido - Japão - Leste Asiático (Japoneses do Norte) } \\ \text { Japão Sul } & \text { SJA } & \text { Norte de Kyushu - Japão - Leste Asiático (Japoneses do Sul) } \\ \text { Hainan } & \text { HAI } & \text { Região do Cantão - Ilha ao Sul da China } \\ \text { Anyang } & \text { ANY } & \text { Dinastia Shang da China - Província de Honan } \\ \text { Santa Cruz } & \text { STC } & \text { Maior ilha do canal de Santa Bárbara - Califórnia - EUA } \\ \text { Peru } & \text { PER } & \text { Província de Yauyos - Peru - Noroeste dos Andes } \\ \text { Arikara } & \text { ARI } & \text { Sítio Sully - Região central do Estado de Dakota do Sul - EUA } \\ \text { Ainu } & \text { AIN } & \text { Sul e sudeste de Hokkaido - Japão - Leste Asiático (Ainu ou Jommon tardios) } \\ \text { Buriat } & \text { BUR } & \text { Sul do Lago Baikal - Sibéria (Buriat) } \\ \text { Esquimó } & \text { ESK } & \text { Oeste e Sudeste da Groenlândia - associação com a cultura Inugsuk } \\ \text { Austrália } & \text { AUS } & \text { Lago Alexandrina - Sul da Austrália - } \\ & & \text { Aborígenes (Jarildekald e Warki-Koroalde) } \\ \text { Tasmânia } & \text { TAS } & \text { Tasmânia - Oceania (Tasmanianos) } \\ \text { Tolai } & \text { TOL } & \text { Península Gazelle - Nova Bretanha - Melanésia (Territórios Tolai) } \\ \text { Atayal } & \text { ATA } & \text { Sul da Tailândia - Leste Asiático (Aborígenes Tailandeses) } \\ \text { Filipinos } & \text { PHI } & \text { Luzon e Mindoro - Illhas Filipinas - Pacífico Sul (Filipinos) } \\ \text { Guam } & \text { GUA } & \text { Costa oeste da baía de Tumon em Guam - Micronésia - Pacífico Sul } \\ \text { Andaman } & \text { ADA } & \text { Ilhas Andaman - Indonésia - Oceano Índico } \\ \text { Maori Sul } & \text { SMA } & \text { Nova Zelândia - Ilha do Sul } \\ \text { Maori Norte } & \text { NMA } & \text { Nova Zelândia - Ilha do Norte } \\ & & \end{array}$


Revista de Antropologia, São Paulo, USP, 2004, v. 47 no 1.

\section{Tabela IV}

Resultados obtidos a partir de 100 subamostragens sem reposição (bootstrap) de 11 amostras mundiais de referência

\begin{tabular}{lccccc}
\hline \multicolumn{3}{c}{ CVs Masculinos } & \multicolumn{2}{c}{ CVs femininos } \\
& Originais & Subamostrais* & & Originais & Subamostrais** \\
\hline NOR & $7,34 \%$ & $7,21 \% \pm 0,07 \%$ & NOR & $6,98 \%$ & $6,78 \% \pm 0,07 \%$ \\
DOG & $8,26 \%$ & $8,05 \% \pm 0,08 \%$ & DOG & $8,06 \%$ & $7,90 \% \pm 0,09 \%$ \\
TAS & $6,92 \%$ & $6,92 \% \pm 0,06 \%$ & TAS & $7,24 \%$ & $7,05 \% \pm 0,08 \%$ \\
BUR & $7,85 \%$ & $7,68 \% \pm 0,07 \%$ & BUR & $7,65 \%$ & $7,42 \% \pm 0,08 \%$ \\
MOK & $6,94 \%$ & $6,82 \% \pm 0,06 \%$ & MOK & $6,89 \%$ & $6,69 \% \pm 0,07 \%$ \\
PER & $7,30 \%$ & $7,09 \% \pm 0,07 \%$ & PER & $7,53 \%$ & $7,26 \% \pm 0,07 \%$ \\
NJA & $7,82 \%$ & $7,59 \% \pm 0,10 \%$ & NJA & $7,94 \%$ & $7,71 \% \pm 0,06 \%$ \\
GUA & $6,71 \%$ & $6,49 \% \pm 0,07 \%$ & GUA & $6,49 \%$ & $6,23 \% \pm 0,07 \%$ \\
ADA & $7,22 \%$ & $7,00 \% \pm 0,08 \%$ & ADA & $7,23 \%$ & $7,00 \% \pm 0,08 \%$ \\
AIN & $6,96 \%$ & $6,74 \% \pm 0,06 \%$ & AIN & $7,04 \%$ & $6,87 \% \pm 0,07 \%$ \\
ESK & $7,35 \%$ & $7,24 \% \pm 0,05 \%$ & ESK & $7,61 \%$ & $7,40 \% \pm 0,08 \%$ \\
& & & & &
\end{tabular}

* Subamostras masculinas compostas por 17 indivíduos.

** Subamostras femininas compostas por 15 indivíduos. 
W. A. Neves \& J. P. V. Atui. O mito da homogeneidade biológica...

\section{Tabela V}

Médias dos CVs de 50 variáveis cranianas (30 faciais e 20 neurocranianas) para as séries usadas no trabalho - parcela masculina

\begin{tabular}{|c|c|c|c|c|}
\hline \multirow[b]{2}{*}{ Série } & \multirow[b]{2}{*}{ Sigla } & \multicolumn{3}{|c|}{ Médias dos $\mathrm{CV}$ s para as medidas cranianas } \\
\hline & & Faciais & Neurocranianas & Gerais \\
\hline Bushman & BUS & $8,46 \%$ & $8,54 \%$ & $8,49 \%$ \\
\hline Tapera & TAP & $8,13 \%$ & $8,73 \%$ & $8,37 \%$ \\
\hline Lagoa Santa & LST & $8,12 \%$ & $8,70 \%$ & $8,35 \%$ \\
\hline Dogon & DOG & $7,44 \%$ & $9,50 \%$ & $8,26 \%$ \\
\hline Teita & TEI & $7,32 \%$ & $8,96 \%$ & $7,97 \%$ \\
\hline Zulu & ZUL & $7,26 \%$ & $8,77 \%$ & $7,86 \%$ \\
\hline Buriat & BUR & $7,53 \%$ & $8,33 \%$ & $7,85 \%$ \\
\hline Japão Norte & NJA & $7,70 \%$ & $8,00 \%$ & $7,82 \%$ \\
\hline Japão Sul & SJA & $7,11 \%$ & $8,12 \%$ & $7,51 \%$ \\
\hline Berg & BER & $7,18 \%$ & $7,95 \%$ & $7,49 \%$ \\
\hline Filipinos & PHI & $6,96 \%$ & $8,14 \%$ & $7,43 \%$ \\
\hline Eskimó & ESK & $7,26 \%$ & $7,49 \%$ & $7,35 \%$ \\
\hline Norse & NOR & $6,74 \%$ & $8,24 \%$ & $7,34 \%$ \\
\hline Peru & PER & $6,55 \%$ & $8,43 \%$ & $7,30 \%$ \\
\hline Hainan & HAI & $6,94 \%$ & $7,78 \%$ & $7,28 \%$ \\
\hline Anyang & ANY & $6,96 \%$ & $7,76 \%$ & $7,28 \%$ \\
\hline Egito & EGY & $6,44 \%$ & $8,44 \%$ & $7,24 \%$ \\
\hline Atayal & ATA & $6,85 \%$ & $7,79 \%$ & $7,23 \%$ \\
\hline Andaman & $\mathrm{ADA}$ & $6,54 \%$ & $8,23 \%$ & $7,22 \%$ \\
\hline Maori Sul & SMA & $6,76 \%$ & $7,90 \%$ & $7,22 \%$ \\
\hline Base Aérea & BAS & $6,69 \%$ & $7,85 \%$ & $7,16 \%$ \\
\hline Tasmânia & TAS & $7,08 \%$ & $7,16 \%$ & $7,11 \%$ \\
\hline
\end{tabular}


Revista de Antropologia, São Paulo, USP, 2004, v. 47 no 1.

\begin{tabular}{rllll} 
Zalavar & ZAL & $6,80 \%$ & $7,30 \%$ & $7,00 \%$ \\
Arikara & ARI & $6,28 \%$ & $7,99 \%$ & $6,96 \%$ \\
Ainu & AIN & $6,94 \%$ & $6,98 \%$ & $6,96 \%$ \\
Mokapu & MOK & $6,54 \%$ & $7,53 \%$ & $6,94 \%$ \\
Tolai & TOL & $6,68 \%$ & $7,16 \%$ & $6,87 \%$ \\
Santa Cruz & STC & $6,45 \%$ & $7,45 \%$ & $6,85 \%$ \\
Moriori & MOR & $6,29 \%$ & $7,49 \%$ & $6,77 \%$ \\
Guam & GUA & $6,38 \%$ & $7,20 \%$ & $6,71 \%$ \\
Easter Island & EAS & $6,30 \%$ & $7,06 \%$ & $6,60 \%$ \\
Austrália & AUS & $6,48 \%$ & $6,59 \%$ & $6,52 \%$ \\
Maori Norte & NMA & $6,13 \%$ & $6,45 \%$ & $6,26 \%$ \\
\hline
\end{tabular}

\section{Tabela VI}

Médias dos CVs de 50 variáveis cranianas (30 faciais e 20 neurocranianas) para as séries usadas no trabalho - parcela feminina

\begin{tabular}{rlccc}
\hline & \multicolumn{4}{c}{ Médias dos CVs para as medidas cranianas } \\
Série & Sigla & Faciais & Neurocranianas & Gerais \\
\hline Base Aérea & BAS & $8,34 \%$ & $10,53 \%$ & $9,22 \%$ \\
Lagoa Santa & LST & $9,19 \%$ & $8,93 \%$ & $9,09 \%$ \\
Teita & TEI & $7,27 \%$ & $10,00 \%$ & $8,36 \%$ \\
Bushman & BUS & $7,91 \%$ & $8,84 \%$ & $8,28 \%$ \\
Zulu & ZUL & $7,44 \%$ & $9,04 \%$ & $8,08 \%$ \\
Dogon & DOG & $7,09 \%$ & $9,50 \%$ & $8,06 \%$ \\
Tapera & TAP & $7,30 \%$ & $8,97 \%$ & $7,97 \%$ \\
North Japan & NJA & $7,31 \%$ & $8,87 \%$ & $7,94 \%$
\end{tabular}


W. A. Neves \& J. P. V. Atui. O mito da homogeneidade biológica...

\begin{tabular}{rllll} 
Arikara & ARI & $6,62 \%$ & $9,28 \%$ & $7,69 \%$ \\
Berg & BER & $7,04 \%$ & $8,64 \%$ & $7,68 \%$ \\
Hainan & HAI & $7,17 \%$ & $8,42 \%$ & $7,67 \%$ \\
Buriat & BUR & $6,93 \%$ & $8,72 \%$ & $7,65 \%$ \\
Eskimo & ESK & $7,35 \%$ & $8,02 \%$ & $7,61 \%$ \\
Peru & PER & $6,75 \%$ & $8,70 \%$ & $7,53 \%$ \\
Zalavar & ZAL & $7,12 \%$ & $8,04 \%$ & $7,49 \%$ \\
South Japan & SJA & $7,07 \%$ & $8,10 \%$ & $7,48 \%$ \\
Egypt & EGY & $6,62 \%$ & $8,69 \%$ & $7,45 \%$ \\
Tasmânia & TAS & $6,79 \%$ & $7,91 \%$ & $7,24 \%$ \\
Andaman & ADA & $6,73 \%$ & $7,99 \%$ & $7,23 \%$ \\
Atayal & ATA & $6,63 \%$ & $7,97 \%$ & $7,17 \%$ \\
Ainu & AIN & $7,10 \%$ & $6,95 \%$ & $7,04 \%$ \\
Norse & NOR & $6,69 \%$ & $7,40 \%$ & $6,98 \%$ \\
Easter Island & EAS & $6,57 \%$ & $7,55 \%$ & $6,96 \%$ \\
Tolai & TOL & $6,85 \%$ & $6,95 \%$ & $6,89 \%$ \\
Mokapu & MOK & $6,45 \%$ & $7,55 \%$ & $6,89 \%$ \\
Moriori & MOR & $6,21 \%$ & $7,21 \%$ & $6,61 \%$ \\
Guam & GUA & $5,75 \%$ & $7,61 \%$ & $6,49 \%$ \\
Santa Cruz & STC & $5,97 \%$ & $7,25 \%$ & $6,48 \%$ \\
Austrália & AUS & $6,14 \%$ & $6,86 \%$ & $6,43 \%$ \\
\hline & & & & \\
\hline
\end{tabular}


Revista de Antropologia, São Paulo, USP, 2004, v. 47 no 1.

\section{Tabela VII}

Médias dos CVs de 25 variáveis cranianas (14 faciais e 11 neurocranianas) para as séries utilizadas no trabalho, com a série Baja California adicionada parcela masculina

\begin{tabular}{rlccc}
\hline & \multicolumn{4}{c}{ Médias dos CVs para as medidas cranianas } \\
Série & Sigla & Faciais & Neurocranianas & Gerais \\
\hline Lagoa Santa & LST & $7,56 \%$ & $4,07 \%$ & $6,03 \%$ \\
Bushman & BUS & $7,27 \%$ & $4,30 \%$ & $5,96 \%$ \\
Tapera & TAP & $6,55 \%$ & $3,90 \%$ & $5,38 \%$ \\
Berg & BER & $6,32 \%$ & $4,14 \%$ & $5,36 \%$ \\
Tasmânia & TAS & $6,40 \%$ & $3,88 \%$ & $5,29 \%$ \\
Zulu & ZUL & $6,12 \%$ & $4,22 \%$ & $5,28 \%$ \\
Japão Norte & NJA & $6,13 \%$ & $4,19 \%$ & $5,28 \%$ \\
Maori Sul & SMA & $6,02 \%$ & $4,27 \%$ & $5,25 \%$ \\
Teita & TEI & $6,14 \%$ & $3,92 \%$ & $5,17 \%$ \\
Buriat & BUR & $5,89 \%$ & $4,24 \%$ & $5,16 \%$ \\
Phillipines & PHI & $5,61 \%$ & $4,32 \%$ & $5,04 \%$ \\
Egypt & EGY & $5,82 \%$ & $4,02 \%$ & $5,03 \%$ \\
Japão Sul & SJA & $6,06 \%$ & $3,71 \%$ & $5,02 \%$ \\
Atayal & ATA & $5,99 \%$ & $3,77 \%$ & $5,01 \%$ \\
Ainu & AIN & $6,23 \%$ & $3,39 \%$ & $4,98 \%$ \\
Dogon & DOG & $5,84 \%$ & $3,82 \%$ & $4,95 \%$ \\
Zalavar & ZAL & $5,84 \%$ & $3,69 \%$ & $4,89 \%$ \\
Eskimó & ESK & $5,72 \%$ & $3,83 \%$ & $4,89 \%$ \\
Hainan & HAI & $5,63 \%$ & $3,88 \%$ & $4,86 \%$ \\
Peru & PER & $5,54 \%$ & $3,97 \%$ & $4,85 \%$ \\
Austrália & AUS & $5,70 \%$ & $3,74 \%$ & $4,83 \%$ \\
& & & &
\end{tabular}


W. A. Neves \& J. P. V. Atui. O mito da homogeneidade biológica...

\begin{tabular}{rllll} 
Adaman & ADA & $5,52 \%$ & $3,95 \%$ & $4,83 \%$ \\
Mokapu & MOK & $5,56 \%$ & $3,90 \%$ & $4,83 \%$ \\
Norse & NOR & $5,73 \%$ & $3,67 \%$ & $4,82 \%$ \\
Tolai & TOL & $5,85 \%$ & $3,43 \%$ & $4,79 \%$ \\
Santa Cruz & STC & $5,55 \%$ & $3,73 \%$ & $4,75 \%$ \\
Anyang & ANY & $5,27 \%$ & $3,90 \%$ & $4,67 \%$ \\
Base Aérea & BAS & $5,81 \%$ & $3,16 \%$ & $4,64 \%$ \\
Arikara & ARI & $5,26 \%$ & $3,84 \%$ & $4,64 \%$ \\
Guam & GUA & $5,43 \%$ & $3,62 \%$ & $4,63 \%$ \\
Moriori & MOR & $5,37 \%$ & $3,54 \%$ & $4,56 \%$ \\
Baja California & BCS & $5,01 \%$ & $3,69 \%$ & $4,43 \%$ \\
Ilha da Páscoa & EAS & $5,16 \%$ & $3,50 \%$ & $4,43 \%$ \\
Maori Norte & NMA & $5,44 \%$ & $3,03 \%$ & $4,38 \%$ \\
\hline
\end{tabular}

\section{Tabela VIII}

Médias dos CVs de 25 variáveis cranianas (14 faciais e 11 neurocranianas) para as séries utilizadas no trabalho, com a série Baja California adicionada parcela feminina

\begin{tabular}{rlccc}
\hline & \multicolumn{4}{c}{ Médias dos CVs para as medidas cranianas } \\
Série & Sigla & Faciais & Neurocranianas & Gerais \\
\hline Lagoa Santa & LST & $7,56 \%$ & $4,20 \%$ & $6,08 \%$ \\
Bushman & BUS & $6,77 \%$ & $4,30 \%$ & $5,68 \%$ \\
North Japan & NJA & $6,35 \%$ & $4,31 \%$ & $5,45 \%$ \\
Zulu & ZUL & $6,34 \%$ & $3,91 \%$ & $5,27 \%$ \\
Zalavar & ZAL & $6,24 \%$ & $3,95 \%$ & $5,23 \%$ \\
Dogon & DOG & $6,10 \%$ & $4,02 \%$ & $5,19 \%$
\end{tabular}


Revista de Antropologia, São Paulo, USP, 2004, v. 47 no 1.

\begin{tabular}{|c|c|c|c|c|}
\hline Base Aérea & BAS & $6,06 \%$ & $4,02 \%$ & $5,16 \%$ \\
\hline Berg & BER & $5,87 \%$ & $4,15 \%$ & $5,11 \%$ \\
\hline Buriat & BUR & $5,87 \%$ & $4,10 \%$ & $5,10 \%$ \\
\hline Tasmânia & TAS & $5,98 \%$ & $3,94 \%$ & $5,08 \%$ \\
\hline Ainu & AIN & $6,22 \%$ & $3,58 \%$ & $5,06 \%$ \\
\hline Peru & PER & $5,81 \%$ & $4,02 \%$ & $5,02 \%$ \\
\hline Hainan & HAI & $5,86 \%$ & $3,87 \%$ & $4,98 \%$ \\
\hline Egypt & EGY & $6,05 \%$ & $3,55 \%$ & $4,95 \%$ \\
\hline Atayal & ATA & $5,84 \%$ & $3,82 \%$ & $4,95 \%$ \\
\hline South Japan & SJA & $5,86 \%$ & $3,77 \%$ & $4,94 \%$ \\
\hline Teita & TEI & $5,84 \%$ & $3,75 \%$ & $4,92 \%$ \\
\hline Norse & NOR & $5,90 \%$ & $3,57 \%$ & $4,87 \%$ \\
\hline Arikara & ARI & $5,36 \%$ & $4,19 \%$ & $4,85 \%$ \\
\hline Eskimo & ESK & $5,70 \%$ & $3,63 \%$ & $4,79 \%$ \\
\hline Tolai & TOL & $5,82 \%$ & $3,47 \%$ & $4,78 \%$ \\
\hline Easter Island & EAS & $5,57 \%$ & $3,73 \%$ & $4,76 \%$ \\
\hline Austrália & AUS & $5,43 \%$ & $3,81 \%$ & $4,72 \%$ \\
\hline Tapera & TAP & $5,68 \%$ & $3,47 \%$ & $4,71 \%$ \\
\hline Mokapu & MOK & $5,38 \%$ & $3,83 \%$ & $4,70 \%$ \\
\hline Moriori & MOR & $5,40 \%$ & $3,62 \%$ & $4,62 \%$ \\
\hline Adaman & $\mathrm{ADA}$ & $5,39 \%$ & $3,62 \%$ & $4,61 \%$ \\
\hline Baja California & BCS & $4,96 \%$ & $3,65 \%$ & $4,38 \%$ \\
\hline Guam & GUA & $4,88 \%$ & $3,57 \%$ & $4,30 \%$ \\
\hline Santa Cruz & STC & $4,86 \%$ & $3,53 \%$ & $4,28 \%$ \\
\hline
\end{tabular}


W. A. Neves \& J. P. V. Atui. O mito da homogeneidade biológica...

\section{Figura 1}

Histograma dos CVs médios das variáveis craniométricas das 33 amostras populacionais (o número ao lado da sigla de referência representa o tamanho amostral efetivo de cada população representada)
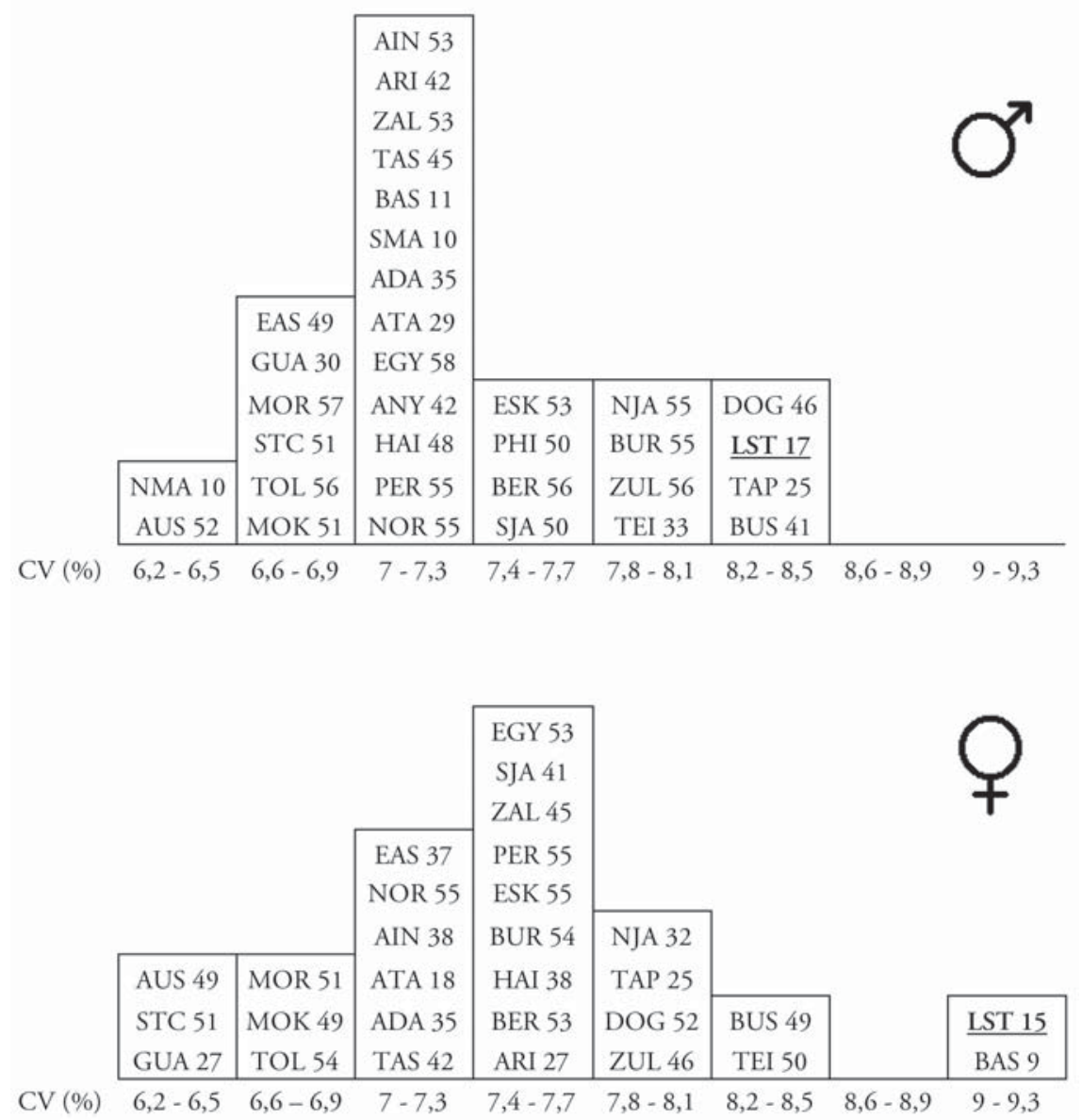
Revista de Antropologia, São Paulo, USP, 2004, v. 47 no 1.

\section{Notas}

1 Os recursos para a execução das pesquisas que deram origem a este trabalho, bem como para sua elaboração final, foram concedidos pela Fapesp, por meio de auxílio a projeto temático (processo 99/00670-7) a Walter A. Neves (WAN), e de bolsa de mestrado (processo 2/04581-3) a João Paulo V. Atui (JPVA). Durante o período, Walter A. Neves recebeu bolsa de produtividade científica do CNPq (processo 305918/85-0). Além dessas instituiçôes, os autores gostariam de agradecer a Ricardo Santos e Hilton Pereira da Silva (Museu Nacional/UFRJ), André Prous e Cláudia Cardoso (Museu de História Natural/UFMG), Rosângela Albano (Centro de Arqueologia de Lagoa Santa), Kim Sorensen Aaris (Museu de Zoologia/Universidade de Copenhague) e Chris Stringer e Robert Krusvinski (Museu de História Natural, Londres), pelo acesso irrestrito às coleçôes de esqueletos humanos da região arqueológica de Lagoa Santa sob suas responsabilidades. Agradecimento especial a Miya Pereira da Silva por ter disponibilizado os dados métricos de Tapera e Base Aérea. Agradecemos ainda a André Prous, pelo incentivo à realização deste trabalho, através de inúmeras conversas informais nos últimos anos; a Mark Hübbe, pela generosa assistência em diversos momentos de sua execução; e, finalmente, mas não menos importante, a W. W. Howells por seu altruísmo ao socializar seu banco de dados na internet. Este trabalho é dedicado a Luis de Castro Faria, por sua grandeza de alma e mente.

2 Bolsista do CNPq (processo 305918/85-0), CP 11461, CEP 05422-970, São Paulo, SP, Brasil, e-mail: waneves@ib.usp.br.

3 Bolsista da Fapesp (processo 2/04581-3), mestrando do Programa de Pós-Graduação em Biologia/Genética, Departamento de Biologia, IB/USP.

4 "Em primeiro lugar foi demonstrado que esses 11 indivíduos pertencem a uma única raça própria" (traduzido do original em alemão por Mark Hübbe, doutorando do LEEH/IBUSP).

5 Claramente intrusivo.

6 Em agosto de 2002, um de nós (WAN), trabalhando sobre fragmentos cranianos humanos da coleção Lund, em Copenhague, reconstruiu mais 13 exemplares mensuráveis. Esses novos crânios receberam numeração de WN-1 a WN-13.

7 O termo "raça paleoamericana" foi introduzido por Deniker (1889) e tem sido readotado nos Estados Unidos como "morfologia paleoamericana" por razōes políticas. 
W. A. Neves \& J. P. V. Atui. O mito da homogeneidade biológica...

8 O homem de Pontimelo faz parte, também, do acervo do Museu de Zoologia da Universidade de Copenhague, integrando a coleção Lawson. Foi encontrado em Arrecifes, próximo ao Rio La Prata, associado à carapaça de um gliptodonte. Tentativas de datar tanto o esqueleto humano quanto a carapaça, levadas a cabo por um de nós (WAN), mostraram-se infrutíferas, tendo em vista a total ausência de colágeno nos ossos.

9 Esse tema foi retomado por Lévi-Strauss, ainda que de passagem, em seu clássico Tristes trópicos.

10 Apesar de Mello e Alvim (1977) ter apresentado em seu trabalho uma tabela na qual os coeficientes de variação de cada índice calculado são mostrados, nenhum tipo de comparação destes CVs com os de outras populações esqueletais foi efetuada.

11 Testes de Qui-quadrado e Exato de Fisher, aplicados sobre essas freqüências numa Tabela 2 x 2, geraram valores não-significativos, variando de $\mathrm{p}=0,19$ a 0,70 .

12 O esqueleto de Escrivânia II da coleção Lund, utilizado por Soto-Heim, foi por

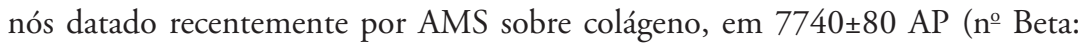
174.734).

13 Todas as dataçôes referem-se a anos radiocarbônicos e não a anos convencionais, conforme a praxe entre os arqueólogos. Em outras palavras, as datações fornecidas não foram calibradas.

14 Note-se que mesmo a população Pericú da Baja California, a qual ficou milhares de anos isolada, tanto que manteve até o século XVI de nossa era uma morfologia muito próxima à dos paleoíndios, teve sua variabilidade intrapopulacional apenas modestamente afetada, similar a outras populaçôes oriundas de ilhas incluídas no trabalho. 
Revista de Antropologia, São Paulo, USP, 2004, v. 47 noo 1.

\section{Bibliografia}

AMBROSE, S. H.

1998 "Late Pleistocene human population bottlenecks, volcanic winter, and differentiation of modern humans, Journal of Human Evolution, vol. 34, p. 623-51

ARAÚJO, A. G. M.; NEVES, W. A. \& PILO, L. B.

2002 "Paleoindian subsistence and technology in Central Brazil: Results from new excavations at Boleiras rockshelter, Lagoa Santa", Current Research in Pleistocene, vol. 19: 4-6.

BASTOS D‘ÁVILA, J.

1950 "Anthropometry of the indians of Brazil", in STEWARD, J. H. (org.), Handbook of South American Indians, Washington D.C., Smithsonian Institution, vol. 6: 71-84.

BEHLING, $\mathrm{H}$.

1998 "Late Quaternary vegetation and climatic change in Brazil", Review of Paleobotany and Palinology, vol. 99: 143-56.

DENIKER, J.

1889 "Essai d'une classification des races humaines, basée uniquement sur les caractères physiques", Bulletins de la Société d'anthropologie de Paris, vol. 12: 320-36.

EFRON, B.

1979 "Bootsrap Method: Another look at the Jackknife", The Annals of Statistics, vol. 7: 1-26.

EHRENREICH, P

1887 "Ueber die Botocudos der brasilianischen Provinzen Espiritu Santo und Minas Geraes”, Zeitschrift für Ethnologie, Berlin, vol. 19: 1-82.

EICKSTEDT, E. F. von

1934 Rassenkunde und Rassengeschichte der Menschheit, Stuttgart, vol. 1: 748-55. 
W. A. Neves \& J. P. V. Atui. O mito da homogeneidade biológica...

FARIA, L. C.

1952 "Pesquisas de antropologia física no Brasil", Boletin do Museu Nacional do Rio de Janeiro (SN), vol. 13: 1-106.

FIGGINS, J. D.

1927 "The antiquity of Man in America", Natural History, vol. 27: 229-39.

GONZÁLEZ-JOSÉ, R.; NEVES, W. A.; HERNÁNDEZ, M.; PUCCIARELI, H. M. \& CORREAL, $\mathrm{U}$.

No prelo "Late Pleistocene/Early Holocene skull from Mexico demonstrate the existence of the Paleoamerican morphological pattern in Mesoamerica", American Journal of Physical Anthropology.

GONZÁLEZ-JOSÉ, R.; GONZALÉZ-MARTÍN, A.; HERNÁNDEZ, M.; PUCCIARELLI, H. M.; SARDI, M.; ROSALES, A. \& VAN DE MOLEN, S.

2003 "Craniometric Evidence for Paleoamerican Survival in Baja California", Nature, vol. 452: 62-5

HANSEN, S.

1888 "Lagoa Santa Racen", in LÜTKEN, C. F. (org.), E Museo Lundii, Forste Bind, Kobenhaun, vol. 5: 1-37

HOWELLS, W. W.

1973 Cranial Variation in Man. A Study of Multivariate Analysis of Patterns of Difference among Recent Human Population. Papers of Peabody Museum of Archaeology and Ethnology, vol. 67, Cambridge, Harvard University.

1989 Skul Shape and the Map. Craniometric Analysis in the Dispersion of Modern Homo. Papers of Peabody Museum of Archaeology and Ethnology, vol. 79, Cambridge, Harvard University.

1995 Who's who in skulls. Papers of Peabody Museum of Archaeology and Ethnology, vol. 82, Cambridge, Harvard University.

HRDLICKA, A.

1912 "The Skeletal Remains of Early Man in South America", HRDLICKA, A. (org.), Early Man in South America, Smithsonian Institution, Bureau of American Ethnology, Bulletin 52, Washington D.C., p. 153-85. 
Revista de Antropologia, São Paulo, USP, 2004, v. 47 no 1.

HUBBE, M.; NEVES, W. A.; ATUI, J. P. V.; CARTELE, C. \& SILVA, M. A. P.

submetido "A new early human skeleton from Brazil: Further support to the 'Two main Biological Components Model' for settlement of the Americas", Current Research in the Pleistocene.

HURT, W. R. \& BLASI, O.

1969 "O projeto arqueológico 'Lagoa Santa', Minas Gerais, Brasil (nota final)", $A r$ quivos do Museu Paranaense (N.S.) Arqueologia, vol. 4: 1-63.

IMBELLONI, J.

1938 "Tabla classificatoria de los indios: regiones biológicas y grupos raciales humanos de América”, Physis, vol. 12: 229-49.

KOLLMAN, J.

1884 "Hohes Alter der Menschenrassen", Zeitschrift für Ethnologie, vol. 16: 181-212.

LACERDA, F. \& PEIXOTO, R.

1876 "Contribuiçôes para o estudo anthropológico das raças indígenas do Brazil", Archivos do Museu Nacional do Rio de Janeiro, vol. 1: 47-79.

LEWONTIN, R. C.

1974 The genetic basis of evolutionary change, New York, Columbia University.

LUND, P. W.

1842 "Carta escripta de Lagôa Santa ao senhor primeiro secretário do Instituto", Revista do Instituto Histórico e Geográfico Brasileiro, vol. 4: 30-87.

1844 "Carta escripta de Lagoa Santa a 21 de abril de 1844", Revista do Instituto Histórico e Geográfico Brasileiro, vol. 6: 334-42.

LÜTKEN, C. F.

1884 "L' Exposition de quelques-uns des crânes et dês autres ossements humains de Minas-Geraés dans le Brésil central découvert et déterrés par e feu Professeur P. W. Lund", Compte-rendu Congré Internationale des Américaniste, Copenhagen, vol. 3: 40-8. 
W. A. Neves \& J. P. V. Atui. O mito da homogeneidade biológica...

MELLO E ALVIM, M. C.

1963 "Diversidade morfológica entre os índios "Botocudos" do leste brasileiro (séc. XIX) e o homem de Lagoa Santa", Boletim do Museu Nacional N.S. Antropologia, Rio de Janeiro, vol. 23: 1-70.

1977 "Os antigos habitantes da área arqueológica de Lagoa Santa (MG-Brasil) - Estudo Morfológico", Arquivos do Museu Nacional de História Natural da Universidade Federal de Minas Gerais, Belo Horizonte, vol. 2: 119-74.

1992-1993 "Os antigos habitantes da Serra do Cipó (MG-Brasil): estudo morfológico preliminar", Arquivos do Museu de História Natural da UFMG, vol. 13/14: 107-28.

MELLO E ALVIM, M. C. \& MELLO FILHO, D. P.

1965 "Morfologia craniana da população do sambaqui da Cabeçuda (Laguna-SC) e sua relação com outras populações de paleoameríndios do Brasil", Homenage a Juan Comas em su 65 aniversário, México.

1967-1968 "Morfologia da população do sambaqui Forte Marechal Luz (Santa Catarina)", Revista de Antropologia, vol. 15/16: 5-12.

MELLO E ALVIM , M. C. \& SOUSA, S. M. F. M. de

1990 "Relaçōes biológicas entre populações indígenas atuais e pré-históricas do Brasil", Clio, vol. 1(6): 69-79.

MELLO E ALVIM , M. C. \& UCHOA, D. P.

1976 Contribuição ao estudo das populaçōes de sambaquis; os construtores de sambaqui de Piaçaguera, São Paulo, Instituto de Pré-História/USP.

1980 "O sambaqui do Buracão: uma contribuição ao estudo da pré-história do litoral paulista”, Arquivos de Anatomia e Antropologia, vol.4/5: 337-93.

MELLO E ALVIM, M. C.; SOARES, M. C. \& CUNHA, P. S. P.

1983-1984 "Traços não métricos cranianos e distância biológica em grupos indígenas interioranos e do litoral do Brasil. 'Homem de Lago Santa', índios Botocudos e construtores de sambaquis", Arquivos do Museu Nacional de História Natural da Universidade Federal de Minas Gerais, vol. 8/9: 323-38.

MESSIAS, T. T. \& MELLO E ALVIM, M. C.

1962 "Contribuiçôes ao estudo do Homem de Lagoa Santa", Boletim do Museu Nacional, N.S. Antropologia, vol. 20: 1-55. 
Revista de Antropologia, São Paulo, USP, 2004, v. 47 no 1.

MUNFORD, D. \& NEVES, W. A.

1994 "Estudo comparativo da morfologia craniana das populações pré-históricas da Sabana de Bogotá: implicações para a questão da ocupação do Novo Mundo", III Congresso Latino-Americano de Antropologia Biológica, Programa e Resumos, 29.

NEVES, W. A.

1980 "Epigenetic variation in Shell-mound builders of the southern Brazil shore", Revista de Pré-história, vol. 2: 93-8.

1988 "Paleogenética dos grupos pré-históricos do litoral sul do Brasil (Paraná e Santa Catarina)", Pesquisas, vol. 43.

NEVES, W. A.; HUBBE, M.; OKUMURA, M. M. M.; GONZÁLEZ-JOSÉ, R.; FIGUTI, L.; EGGERS, S. \& DE BLASIS, P. A. D.

Submetido "Comparative cranial morphology of an early Holocene human skeleton from Southern Brazil”, American Journal of Physical Anthropology.

NEVES, W. A.; POWELL, J. F. \& OZOLINS, E. G.

1999a "Extra-continental morphological affinities of Palli Aike, southern Chile", Interciéncia, vol. 24: 258-63.

1999b "Extra-continental morphological affinities of Lapa Vermelha IV, Hominid 1: A multivariate analysis with progressive number of variables", Homo, vol. 50: 263-82.

NEVES, W. A.; POWELL, J. F.; PROUS, A.; OZOLINS, E. G. \& BLUM, M.

1998 "Lapa Vermelha IV, Hominid 1: Morphological affinities of the earliest known American”, American Journal of Physical Anthropology, Suplemento 26, p. 196.

NEVES, W. A.; PROUS, A. GONZÁLEZ-JOSÉ, R.; KIPNIS, R. \& POWELL, J.

2003 "Early Human skeletal Remains from Santana do Riacho, Brazil: implications for the settlement of the New World", Journal of Human Evolution, vol. 45: $19-42$.

POECH, $\mathrm{H}$.

1938 "Bietrag zur kenntnis von den fössilen meschlichen Funden von Lagoa Santa (Brasilien) und Fontezuelas (Argentinien)”, Mitteilugen der Anthropologischen Gesellschaft, vol. 98: 310-35. 
W. A. Neves \& J. P. V. Atui. O mito da homogeneidade biológica...

POWELL, J. F. \& NEVES, W. A.

1999 "Craniofacial Morphology of the First Americans: Patterns and Processes in the Peopling of the New World", Yearbook of Physical Anthropology, vol. 42: 153-88.

POWELL, J. F.; NEVES, W. A.; OZOLINS, E. G. \& PUCCIARELLI, H. M.

1999 "Afinidades biologicas extra-continentales de los dos esqueletos mas antiguos de América", Antropología Fisica Latinoamericana, vol. 3: 114-27.

PROUS, A.

1978 "L'homme et la nature dans la région de Lagoa Santa (Brésil)", Arquivos do Museu Nacional de História Natural da Universidade Federal de Minas Gerais, vol. 3: 65-93

1990 "Le grand abri de Santana do Riacho", Les dossier d'archéologie, vol. 145: 74-7.

1991 Arqueologia Brasileira, Brasilia, UnB.

PROUS, A. \& FOGAÇA, E.

1999 "Archaeology of Pleistocene-Holocene boundary in Brazil", Quaternary International, vol. 53/54: 21-41.

QUATREFAGES, A.

1879 "L'homme fossile de Lagoa Santa (Brésil) et ses descendants actuels", Congrès Antropologique de Moscou, Moscou, Anais, vol. 3: 321-402.

1881 "L'homme fossile de Lagoa Santa au Brésil et ses descendants actuels", Compte rendus de l'Academie des Sciences de Paris, vol. 93: 882-4.

REINHARDT, J. T.

1868 "Bone caves of Brazil and their remains", American Journal of Sciences, vol. 96: $64-5$.

RELETHFORD, J. H. \& BLANGERO, J.

1990 "Detection of differential gene flow from patterns of quantitative variation", Human Biology, vol. 62: 5-25.

RELETHFORD, J. H. \& HARPENDING, H. C.

1995 "Ancient differences in population size can mimic a recent African origin of Modern Humans", Current Anthropology, vol. 36: 667-74. 
Revista de Antropologia, São Paulo, USP, 2004, v. 47 noo 1.

RIVET, P.

1908 "La race de Lagoa-Santa chez le population precolombiennes de L'Equateur", Bulletins et Mémoires de la société D’Anthropologie de Paris, vol. 19: 209-75.

SARICH, V. M.

1999 "Race and language in prehistory", in CLARK, G. A. \& WILLERMET, C. M. (org.), Conceptual issues in modern human origins research, New York, Aldine Gruyter, p. 392-410.

SCHMITZ, P. I.

1984 Caçadores e coletores da pré-história do Brasil, São Leopoldo, Instituto Anchietano de Pesquisas/Unisinos.

SOTO-HEIM, P.

1994 "Les Hommes de Lagoa Santa (Brésil). Caractères Anthropologiques et position parmi d'autres populations paléoindiennes d'Amérique", L’Anthropologie, Paris, vol. 98, p. 81-109.

TEMPLETON, A.

1993 "The 'Eve' hypotheses: a genetic critique and reanalysis", American Anthropologist, vol. 95: 51-72.

TEN KATE, M. H.

1885 "Sur les crânes de Lagoa Santa", Bulletins de la Société d'Anthropologie de Paris, vol. 18: 240-6.

VAN VARK, G. N.; KUIZENGA, D. \& WILLIAMS, F. L. E.

2003 "Kennewick and Luzia: Lessons from the European Upper Paleolithic", American Journal of Physical Anthropology, vol. 121: 181-4.

WRIGHT, S.

1931 "Evolution in Mendelian Populations", Genetics, vol. 16: 97-159.

1943 "Isolation by distance", Genetics, vol. 28: 114-38. 
W. A. Neves \& J. P. V. Atui. O mito da homogeneidade biológica...

ABSTRACT: Since their first discovery in 1842-1843, by Peter Lund, the human skeletal remains from Lagoa Santa, Brazil, were destined to influence, substantially, the discussion about the settlement of the Americas, from a biological perspective. Until 1970 several authors have refered to these remains as a homogenous collection, implying that these individuals represented just one biological population or "race". Mello e Alvim (1977; see also Mello e Alvim et al., 1983-1984) was the first to use explicitly the term "homogeneity" as implying a very low intra-population diversity among these late paleoindians. For her, the extremely low diversity among the Lagoa Santa specimens could be explained only by a narrow bottle neck occuring during the occupation of the region, followed by geographic isolation from other contemporary groups. The idea of a extremely low diverse population in ancient Lagoa Santa led some brazilian archeologists to elaborate on the "isolation hypothesis", and to use it to explain local characteristics of material culture and social organization. In this paper we show that even very simple quantification techniques is able to demonstrate that the Lagoa Santa early inhabitants are among the most diverse populations in the planet, as it is normally the case with Late Pleistocene/Early Holocene hunter-gatherers.

KEY WORDS: within-population variability, Paleoindians, Coeficient of Variation, genetic isolation.

Aprovado em março de 2004. 